\title{
Importance of Opportunistic Health-Checks among Lower Socioeconomic Groups
}

\author{
Hyun S. Lee* \\ GKT School of Medical Education, King's College London, London, UK
}

\section{Dear Editor,}

I was fascinated by an article of Shin et al. ${ }^{1)}$ published in the March issue. As a Korean national studying medicine in the United Kingdom, I noticed that the authors' use of the National Health Service's (NHS) Health Check Program as a reference point was misplaced. Korea's current health check-up and screening programs are far more thorough than those of the NHS Health Check Program, which is implemented just once every 5 years and the laboratory tests are limited to cholesterol and hemoglobin Alc levels. ${ }^{2)}$ Most NHS preventive measures are opportunistic, which is an area where Korea could improve.

Unlike Korea's quasi-public healthcare system, the United Kingdom operates on a single-payer system in which patients have no costs other than through taxation. All NHS patients are registered with general practitioners and allocated to dedicated general practitioners who are remunerated via a complex system of base fees per patient and outcome-based incentives, which are set forth in the Quality Outcomes Framework (QOF). ${ }^{3)}$ Example incentives are annual asthma checkups and blood pressure monitoring of diabetic patients. To earn the maximum possible income, practitioners proactively seek patients for check-ups, usually using nurses.

Korea's current primary care system encourages as many patient encounters as possible because remuneration primarily is on a per patient visit basis. Therefore, clinicians have little incentive to thoroughly read individual patients' histories or perform opportunistic reviews of chronic conditions outside the purposes of the visit. This differs from the United Kingdom, where digital patient records actively alert clinicians of outstanding items in the QOF, which fully exploits a consultation's opportunities. For example, a chronic asthma patient seeking care for something unrelated to asthma would obtain an asthma review. Health outcomes are thereby improved.

This is a highly relevant approach from the perspective of healthcare service use among people of relatively low socioeconomic status because they tend to seek care less often, ${ }^{4)}$ usually because of financial or other personal constraints. Rather than trying to improve national screening programs to improve healthcare for these patients, a better approach might be to increase their access to opportunistic health check-ups during scheduled visits. This approach would improve health outcomes better than public information campaigns targeting lower socioeconomic groups, and it would function well given the lack of continuity in the Korean primary care system.

\section{CONFLICT OF INTEREST}

No potential conflict of interest relevant to this article was reported.

\section{ORCID}

Hyun S. Lee: https://orcid.org/0000-0002-8425-0706

\section{REFERENCES}

1. Shin HY, Kang HT, Lee JW, Lim HJ. The association between socioeconomic status and adherence to health check-up in Korean adults, based on the 2010-2012 Korean National 
Health and Nutrition Examination Survey. Korean J Fam Med. 2018;39:114-21.

2. Public Health England. NHS health check: best practice guidance. London: Public Health England; 2017.

3. The King's Fund. Commissioning and funding general practice: making the case for family care networks [Internet]. London: The King's
Fund; 2014 [cited 2018 Jun 20]. Available from: https://www.kingsfund. org.uk/publications/commissioning-and-funding-general-practice.

4. Filc D, Davidovich N, Novack L, Balicer RD. Is socioeconomic status associated with utilization of health care services in a single-payer universal health care system? Int J Equity Health 2014;13:115. 